\title{
Factor I Inactivation
}

National Cancer Institute

\section{Source}

National Cancer Institute. Factor I Inactivation. NCI Thesaurus. Code C131660.

Presence of inactivating antibodies to fibrinogen (factor I) in the blood. 